\title{
VARIAÇÕES ANATÔMICAS DO CANAL MANDIBULAR
}

Felipe BELTRAMINI; Mariana C. S. WAGNER; Vanessa Wisniewski VIANNA; Ângela FERNANDES

O trabalho irá apresentar a prevalência dos diferentes trajetos do canal mandibular, tendo por objetivo destacar já conhecidas variações anatômicas do canal mandibular e informar os profissionais da área da saúde quanto à existência das mesmas, bem como suas condutas clínicas frente a esses achados anatômicos. Foram avaliadas 211 radiografias panorâmicas de pacientes atendidos no curso de odontologia da UFPR no período de 2005 a 2006. Os pacientes eram brasileiros, de ambos os sexos, com idades entre 7 e 84 anos. As radiografias foram avaliadas por 3 pesquisadores após calibração prévia, sobre negastocópio adequado. Utilizou-se a classificação de LANGLAIS et al (1985). Das 211 radiografias avaliadas 2,36\% (5 casos) apresentaram canal mandibular ramificados, sendo que destes 2 apresentavam ramificação para o terceiro molar bilateralmente, 1 ramificação para o terceiro molar unilateralmente e 1 ramificação limitada ao ramo mandibular bilateralmente. Pode-se confirmar que o canal mandibular pode apresentar variações em sua trajetória, sendo extremamente importante a verificação criteriosa do mesmo em radiografias panorâmicas prévias ao tratamento a fim de se estabelecer um plano de tratamento adequado para o paciente. 